Editorial

\title{
Head injuries
}

\section{J Dvorak, A Junge, P McCrory}

\section{Do heading and head injuries in football lead to long term cognitive impairment?}

ta football, contact to the head during tackling duels or when heading the ball has the potential to cause traumatic brain injury. Alongside specific concerns related to individual incidents causing concussion there is also a wider debate of whether repeated concussive and subconcussive head trauma may lead to chronic brain injury.

This issue was first raised in a series of retrospective studies involving retired Scandinavian football players where cognitive deficits were noted. ${ }^{12}$ In these studies, significant methodological problems such as the lack of pre-injury data, selection bias, failure to control for acute head injuries, lack of observer blinding, and inadequate control subjects flawed the results. Although the authors concluded that the deficits noted in the former football players were explained by repetitive trauma such as heading the ball, the pattern of deficits is equally consistent with alcoholrelated brain impairment, a confounding variable that was not controlled for.

Matser and colleagues from the Netherlands have also implicated both concussive injury and heading as a cause of neuropsychological impairment in both amateur and professional football players. ${ }^{3-5}$ Reanalysis of the data from these papers however suggests that purposeful heading may not be a risk factor for cognitive impairment. ${ }^{6}$ Data from Norway using video analysis of head injury incidents demonstrates that the commonest cause of concussive trauma is contact between the upper limb and head during tackling duels rather than head to head contact as may be intuitively suspected. ${ }^{7}$

Prospective controlled studies in football have failed to find any evidence of cognitive impairment in the players using clinical examination, neuroimaging, or neuropsychological testing. ${ }^{8-10}$ In part this may be explained by changes in the game such as the move away from the older, leather, water absorbing, and heavier ball to the modern, synthetic, water resistant, and lighter ball.
In a recent review of the literature, Rutherford et al concluded ${ }^{11}$ :

that presently, although there is exploratory evidence of sub-clinical neuropsychological impairment as a consequence of football-related concussions, there is no reliable and certainly no definitive evidence that such impairment occurs as a result of general football play or normal football heading. The neuropsychological consequences of footballrelated sub-concussive effects await confirmatory investigation.

The conflicting results in the scientific literature motivated the Fédération Internationale de Football Association (FIFA) Medical Assessment and Research Centre (F-MARC) to develop a coordinated research programme to understand further the relationship between heading, head injury, and cognitive deficits. The programme was designed to:

- study the epidemiology of the head and brain injuries

- understand the mechanism leading to injury

- identify if there are changes in brain function due to heading and/or head injuries in professional football players.

F-MARC has also been centrally involved in the development of international consensus evidence-based guidelines for the management of sportrelated concussive brain injury. ${ }^{12}{ }^{13}$ This supplement of the British Journal of Sports Medicine covers the areas described below.

FREQUENCY OF HEAD AND NECK INJURIES IN FIFA COMPETITIONS

The objective of this six year prospective study was to identify those risks that have the greatest impact on the frequency of head and neck injuries in international football competitions. Twenty FIFA competitions (men and women) from 1998 to 2004 were analysed using the database obtained by
F-MARC from the team physicians' reports. Video recordings of the incidents leading to head injuries were analysed to identify the different parameters of injury causation, while the team physicians provided medical reports describing the nature and diagnosis of the head and neck injuries.

\section{BIOMECHANICAL INVESTIGATION OF} HEAD IMPACTS

The scientific literature available offers a small amount of information with regard to the forces that are generated when heading a football and the head and brain response to the different types of impact. Methods of biomechanical measurement and a mathematical model were developed to provide insight into the head impact response and the influence of heading techniques as well as the effect of ball properties on head response. The mathematical model allows simulation of incidents leading to head and brain injuries. It has been developed based upon the data obtained from the video analysis and measurements of heading the ball under laboratory conditions and/or experiments with human surrogates. The investigation concluded that the current accepted heading techniques and training are appropriate, and no firm recommendation can be made to alter existing heading techniques.

Furthermore, investigation of the properties of the different balls that were used in the FIFA World Cup from 1974 to 2002 under dry and wet conditions has clearly shown that the ball mass, pressure, and, in particular, the construction of the ball can reduce the severity of the impact to the head and neck.

In the next step of the biomechanical investigation typical cases of head impact were selected from video footage provided by F-MARC and were analysed by simulating the incidents on an instrumented model.

\section{EFFECTS OF HEADING EXPOSURE AND PREVIOUS CONCUSSIONS ON NEUROPSYCHOLOGICAL PERFORMANCE}

The issue of neuropsychological performance in professional football players has been examined. All the players participating in the professional football league performed two consecutive baseline neuropsychological tests prior to the season in 2004. The number of previous concussions was positively associated with lifetime heading exposure, but there was no relation between previous concussion and test performance. In conclusion, the computerised neuropsychological testing revealed no evidence of neuropsychological impairment due to heading exposure or previous 
concussion in the examined group of football players.

\section{THE VALUE OF NEUROPSYCHOLOGICAL TESTING AFTER HEAD INJURIES}

Neuropsychological test batteries have been added to the management of sports concussion to provide objective information about both diagnosis and recovery following injury. Given the wide range of factors that can influence test performance, the most accurate interpretations can be made when an individual's results are compared with his or her own baseline. At present a variety of traditional pencil and paper protocols and newer computerised test batteries exist. An understanding of the limitations and interpretation of such tests will assist the clinician in the use of these tests as an adjunct to clinical assessment.

\section{CONSENSUS ON CONCUSSION IN SPORT}

In collaboration with the International Ice-Hockey Federation and the International Olympic Committee, a follow up conference of the first consensus conference on concussion in sport was held in Prague, Czech Republic, in November 2004. To facilitate the suspected diagnosis of football concussions, a simple sideline assessment method was presented to both medical and non-medical personnel-the sideline concussion assessment tool (SCAT). In the case of a concussion the player should not be allowed to return to play in the current game or practise session, and he or she should be regularly monitored for deterioration and medically evaluated. The return to play must follow a medically supervised stepwise process.

The issue of sports and football concussion management is continually evolving and the usefulness of expert agreement in establishing a standard of care has been demonstrated by the Vienna Consensus in 2001 and the Prague Agreement in 2004. ${ }^{12}{ }^{13}$ The consensus group expect that standards for diagnosis and care will continue to be revised and updated at future meetings.

Br J Sports Med 2005;39(Suppl I):i1-i2. doi: $10.1136 / \mathrm{bjsm} .2005 .021188$

Authors' affiliations

J Dvorak, A Junge, Schulthess Klinik, Zurich, Switzerland

P McCrory, University of Melbourne,

Melbourne, Victoria, Australia

Correspondence to: Professor J Dvorak Schulthess Klinik, Zurich, Switzerland; jiri.dvorak@kws.ch

\section{REFERENCES}

1 Tysvaer A, Storli O, Bachen N. Soccer injuries to the brain: a neurologic and encephalographic study of former players. Acta Neurol Scand 1989;80:151-6

2 Tysvaer AT. Head and neck injuries in soccer the impact of minor head trauma. Sports Med 1992:14:200-13.

3 Matser EJ, Kessels AG, Lezak MD, et al. Neuropsychological impairment in amateur soccer players [see comments]. JAMA 1999;282:971-3.

4 Matser JT, Kessels AGH, Jordan BD, et al. Chronic traumatic brain injury in professional soccer players. Neurology 1998;51:791-6.

5 Matser JT, Kessels AGH, Lezak MD, et al. A doseresponse relation of headers and concussions with cognitive impairment in professional soccer players. J Clin Exp Neuropsychol 2001;23:770-4.

6 Kirkendall DT, Garrett WE. Heading in soccer: integral skill or grounds for cognitive dysfunction? J Athl Train 2001;36:328-33.

7 Andersen T, Arnason A, Engebretsen L, et al. Mechanism of head injuries in elite football. Br J Sports Med 2004:38:690-6.

8 Jordan BD. Acute and chronic brain injury in United States national team soccer players. Am J Sports Med 1996;24:704-5.

9 Putukian M, Echemendia R, Mackin S. The acute neuropsychological effects of heading in soccer. Clin J Sports Med 2000;10:104-9.

10 Guskiewicz K, Maskell S, Broglio S, et al. No evidence of impaired neurological performance in collegiate soccer players. Am J Sports Med 2002;30:157-62.

11 Rutherford A, Stephens R, Potter D. The neuropsychology of heading and head trauma in Association football (soccer): a review. Neuropsychol Rev 2003;13:153-79.

12 Aubry M, Cantu R, Dvorak J, et al. Summary and agreement statement of the first International Conference on Concussion in Sport, Vienna 2001. Br J Sports Med 2002;36:6-10.

13 McCrory P, Johnston K, Meeuwisse W, et al. Summary and agreement statement of the second International Conference on Concussion in Sport, Prague 2004. Br J Sports Med 2005;39(Suppl I): i78-i86. 